\title{
Teaching and learning about women and leadership: Students' expectations and experiences
}

\author{
S. Lynn Shollen \\ Christopher Newport University \\ Newport News, VA 23606 \\ lynn.shollen@cnu.edu
}

\begin{abstract}
Qualitative, case study methods were used to examine students' expectations of and experiences with studying women and leadership. Participants were 48 undergraduate students enrolled in an elective course titled Women and Leadership offered in the Leadership Studies minor curriculum at a liberal arts institution. Students perceived women and leadership as a sensitive subject fraught with potential struggles for learners, but were willing to engage in the subject in pursuit of both meaningful learning and their own utilitarian-oriented leadership development. Their experiences show the potential for transformative learning if the course content, structure, and learning environment are purposefully crafted to enable students to deal with anticipated or experienced struggles and engage in rather than resist the learning experience. The findings have implications for leadership curriculum design, course design, and pedagogy. Although this study focused on undergraduate learners in a traditional college classroom, the implications may also be relevant to a range of leadership educators and learners in various educational contexts both within and outside of academe.
\end{abstract}

\section{Introduction}

As the leadership industry grows, leadership education programs are proliferating in both academic and non-academic settings (Kellerman, 2012; Schwartz, Axtman, \& Freeman, 1998). Curricular programs address the interdisciplinary construct and practice of leadership from various angles (e.g., Riggio, Ciulla, \& Sorenson, 2003). One angle at times formally addressed in the curriculum is studying leadership from the perspective of sex and gender. (Technically, the term sex refers to biological and physiological characteristics that define females and males, or less frequently, both sexes simultaneously in the case of intersexual individuals. The term gender refers to socially constructed, and therefore culturally influenced, roles and behaviors performed by and expected of individuals. Although gender identity often aligns with biological sex (i.e., cisgender or cissexual), it does not necessarily (e.g., transgender, transsexual, androgynous). At the risk of doing disservice to the complexity of how an individual may navigate sex and gender, this paper focuses on gender, and does so in the reductionist manner of categorizing gender as woman or man rather than on a spectrum.) In addition, numerous programs specifically for educating current or aspiring women leaders are increasingly being offered by leadership educators both inside and outside of academe (Ely, Ibarra, \& Kolb, 2011). 
Leadership educators may not recognize the potential for gender to be a sensitive identity to scrutinize; thus, they may not adjust the approach to developing or teaching a gender-focused course. The topic of gender may also simply be avoided. Rusch argues that "as faculty design leadership programs and plan courses, discourse about gender and race is often limited or treated as a taboo subject" (2004, p. 14). Courses or other leadership development initiatives focused on women and leadership tend to be advocated for, developed, and taught by women who are likely comfortable and versed in talking openly about gender issues. However, if women and leadership is addressed as a portion of another course or of a larger leadership development series outside of academe, it may be that the instructor is unaware of the potential for the issues to be sensitive or not equipped to deal with the challenges of teaching sensitive issues.

Even if an instructor is willing to address gender, students may resist digging into the issues (Crosby, 2012; Lusk \& Weinberg, 1994). Beyond leadership courses in a traditional higher education setting, adult learners taking part in structured leadership development experiences may be just as resistant to engaging with issues of gender. Resistance may even be heightened if learners are participating in the experience with co-workers; some leadership educators advocate for women-only leadership development opportunities to minimize resistance (e.g., Debebe, 2011; Vinnicombe \& Singh, 2002). Resistance can inhibit learning because engagement contributes to a variety of desirable learning outcomes (Carini, Kuh, \& Klein, 2006), and requires students to be willing and compelled to participate and be successful in the learning process (Bornia et al., 1997). Engagement must occur if transformative learning is to result (Mezirow, 1997), which is likely a goal for those teaching about women and leadership.

While there is a wealth of literature on teaching relevant to sensitive identities such as gender and race, and on the subject of women and leadership and developing women leaders, there is little about teaching women and leadership as a potentially sensitive subject (see Brown, Irby, Fisher, \& Yang, 2006; Debebe, 2011; Ely et al., 2011). It is essential for leadership educators who take on the challenge of developing and teaching curricula, courses, and programs about women and leadership to understand students' perspectives on learning about the subject. This study's purpose is to examine students' expectations of and experiences with studying women and leadership. Although this study focuses on undergraduate students enrolled in a women and leadership course offered in a traditional college classroom, it is relevant to leadership educators and learners in various educational contexts within and outside of academe.

\section{Relevant Literature}

To support the study's purpose, I examined literature relevant to three areas: (a) women and leadership as a sensitive subject; (b) teaching sensitive issues; and (c) transformative learning.

Women and Leadership as a Sensitive Issue. It is widely accepted that in general women and men experience leading and leadership differently (Rhode, 2003), and "aspiring women leaders have less social support for learning how to credibly claim a leader identity" (Ely et al., 2011, p. 477). These notions themselves may not be sensitive; however, many of the underlying issues can be. To start, it is usually necessary to accept generalizing about gender in order to study the issues. For example, women typically experience a double bind that men do 
not. Women must balance being perceived as both likeable (feminine enough) and competent (masculine enough) in order to be perceived as effective leaders; and, they tend to have to work harder to be perceived as qualified, effective, or competent as men (Eagly \& Carli, 2007). That harder work is also often accompanied by a disproportionate responsibility for childcare and home life. This pressure not only to "do it all," but to do each part of "it all" perfectly, often inclines women to take "scenic routes" or "off ramps" in the work force and leadership roles, and to avoid "leaning in" along the path to positions of power and influence (Hewlett, 2007; Sandberg, 2013; Slaughter, 2012; Spar, 2013). Further, many organizations still operate with outdated assumptions of the traditional employee and family — a man with a geographically mobile wife at home to deal with home and caretaking responsibilities - which often does not provide a structure or culture that supports women employees in fulfilling all of their work and home responsibilities (Hewlett, 2007).

The aforementioned gendered issues around leadership can elicit stirrings of discomfort. If those issues are uncomfortable, then others can truly be sensitive to explore. For example, arguments that blatant and subtle sex discrimination still exist; that women should fill their traditional social role instead of trying to do it all; that compared to men, women may actually be better equipped for leadership given their typically collaborative qualities (Helgesen, 1990) —an argument that persists despite meta-analyses that show only slight, context-specific leadership style differences between men and women (Eagly, Johannesen-Schmidt, \& van Engen, 2003; Eagly \& Johnson, 1990); and, that women may be hired or promoted over men as "token" representatives of gender diversity to make an organization look good (Eagly \& Carli, 2007).

To be fair, not all discourse about women and leadership focuses on difference and struggle. A growing body of scholarship proposes the idea of degendering leadership, or figuring out what leadership could look like as a gender-neutral construct, as well as appreciating both similarities and differences among genders, and focusing on the strengths, which may or may not be gender-related, that an individual brings to leadership (e.g., Pittinsky, Bacon, \& Welle, 2007). Further, some organizations are priding themselves on hiring, supporting, and developing women for leadership opportunities (Sharpe, 2000; Tuhus-Dubrow, 2009).

Teaching Sensitive Issues. Teachers play an important role in facilitating the exploration of controversies and sensitive issues as a critical component of democratic education (Gutman, 1988). They are responsible for providing the opportunity and structure for students to learn how to engage and work through controversy (Cherrin, 2004). That responsibility comes with added emotional challenge and risk, but also notable rewards (Gilbert \& Eby, 2001). Although classrooms, particularly in leadership preparation programs, serve as laboratories for engaging in complex conversations on a smaller scale, classroom discourse about sensitive identities such as gender and race remains difficult and is often avoided (Rusch, 2004). In a study of educational administration faculty, Rusch found that even in discussions among faculty outside of the classroom, faculty feared making incorrect or offensive comments, experiencing discomfort from awkward conversations, and creating conflict. These fears, along with the added emotional challenge and risk, are reasons many faculty behave as though the sensitive issues don't exist. 
If faculty are courageous enough to approach sensitive topics in the classroom, students often resist. Although some students may simply be uninterested, more likely they fear negative consequences of participating in discussions of sensitive topics. Lusk and Weinberg (1994) categorize the reasons students are reluctant to participate: (a) potential repercussions of disagreeing with or offending the professor; (b) fear that disagreements inside the classroom will affect peer interactions beyond the classroom; and (c) belief that she/he does not have the appropriate level of expertise to contribute to the discussion, and as a result will appear foolish if choosing to speak up. Further, social norms ingrained from a young age contribute to the challenges of discussing sensitive topics. An exercise designed to get to the root of the resistance revealed that social norms such as showing respect for others, being nonconfrontational, being liked, not speaking out of ignorance, classroom discussions being debate rather than dialogue, and avoiding emotions and subjectivity in rational discussions shaped students' hesitancy to engage in discussions of gender and race issues (Lusk \& Weinberg, 1994).

Numerous approaches to teaching sensitive issues are designed to help students become more comfortable discussing issues of gender and race (see Brookfield, 1995; Cherrin, 2004; Cotton, 2006; Crosby, 2012; Gilbert \& Eby, 2001; Jakubowski, 2001; Lusk \& Weinberg, 1994; Pace, 2003). After all, when teaching sensitive material, an optimal classroom environment is one in which students are free to share their own opinions and experiences, while being accountable for remaining open to and respectful of other students and their opinions (Cherrin, 2004). Unfortunately, achieving such openness is easier said than done. Even if students manage the courage to discuss sensitive issues, they often feel compelled to hide their sensitive identities that may inform those discussions. Canagarajah (2004) describes classrooms and schools as "power-laden sites" in which students feel pressure to conform to socially acceptable, institutionally desired identities and uphold the corresponding dominant discourses (p. 120).

Transformative Learning. In general, learning is a process that results in a change in knowledge, beliefs, behaviors, or attitudes (Ambrose, Bridges, DiPietro, Lovett, \& Norma, 2010). The complex learning process is influenced by numerous variables related to, among other areas, the student, classroom, instructor, home, and community (Wang, Haertel, \& Walberg, 1990); level of student engagement (Kuh, Kinzie, Schuh, \& Whitt, 2010); faculty's educational practices (Umbach \& Wawrzynski, 2005); educational leadership of the institution in which formal learning takes place (Leithwood, Louis, Anderson, \& Wahlstrom, 2009); institutional or organizational culture (Kuh, 1993); and, societal culture and identity-based cultural practices (Lee, 2009). Indeed, the learning process can be influenced by many other factors beyond those noted here.

Mezirow (2000) theorizes that transformative learning goes beyond knowledge acquisition or behavior change associated with general learning. Transformative learning, which could occur suddenly or progressively, to some extent always entails an epistemological change, or change in an individual's "way of knowing." For learning to be transformative, an individual's taken-for-granted frames of reference, such as personal paradigms, habits of mind, and assumptions, must be modified to be "more inclusive, discriminating, open, emotionally capable of change, and reflective so that they may generate beliefs and opinions that will prove more true or justified to guide action" (Mezirow, 2000, pp. 7-8). The result is a fundamental, qualitative difference in habits of mind or paradigmatic assumptions, beyond a more informed or 
deeper understanding of a topic or idea.

Frames of reference are transformed through constructive discourse and critical reflection with others and self (Mezirow, 2000). Whereas Mezirow emphasizes the role of constructive discourse as allowing for a rational examination of current frames of reference and exploring alternatives in a safe space, other scholars contend that the affective dimension of knowing, which involves the role of emotions and feelings in the transformation process, requires equal attention (Taylor, 2000a). Indeed, although transformative learning "may be experienced as exhilarating and energizing it is also, at times, traumatic and overwhelming. Changing how one knows risks changes in everything one knows about... in short, the totality of one's adult commitments" (Taylor, 2000b, p. 160). To cope with the affective dimension, constructive discourse within a context of trustful relationships is essential (Taylor, 2000a).

Reflecting critically on the source, nature, and consequences of assumptions is also necessary for transformative learning. Critiquing one's own assumptions and deeply held truths is not easy (Mezirow, 2000). Despite the challenges, research supports the necessity of constructive discourse and critical reflection for transformative learning, and for those elements to occur under learning conditions that are democratic, open, and rational. Taylor (2000a) reviews research that indicates other important conditions, such as need for teachers to be trusting, empathetic, caring, authentic, sincere, and of high integrity; emphasis on personal selfdisclosure; need to discuss and work through emotions and feelings before critical reflection occurs; importance of feedback and self-assessment, solitude, and self-dialogue; and, need for experiential learning activities. Further, both students and teachers must be willing to invest time, take risks, engage in personal exploration, and handle intense experiences. Personal and sociocultural context also shape transformative learning experiences (Taylor, 2000a). A wealth of literature on the process and challenges of transformative learning is available for interested readers, but a review is beyond the scope of this paper.

\section{Methods and Design}

This study was designed to investigate students' expectations of and experiences with a course on women and leadership. This section is divided into two subsections: Study Methods and Study Design.

Study Methods. I utilized qualitative, case study methods to pursue the purpose of this study. I chose a case study approach because this study's focus required the methods to capture a bounded context for the phenomenon being studied (Miles \& Huberman, 1994). The focus also required participants that were immersed in a purposive and convenient context (Marshall \& Rossman, 2011). I chose qualitative methods because they support the aim of understanding process (Merriam, 1998), and are ideal for revealing and understanding complexities behind a phenomenon (Strauss \& Corbin, 1990). Because I sought to understand rather than manipulate relevant behaviors and perceptions, qualitative, case study methods allowed me "to retain the holistic and meaningful characteristics of real-life events" (Yin, 2009, p. 4).

Ethical and practical implications related to my dual roles of instructor and researcher were addressed. Participants were made aware of my position and the nature of the study, 
participated voluntarily, and were assured that neither data gathered for research purposes nor non-participation would affect their grades (Miles \& Huberman, 1994). Participants were also assured that they could opt out of the study at any time during the semester without consequence.

Study Design. In this section, the study design is described in the following subsections: (a) Setting described; (b) Participants described; (c) Data collection; and (d) Data analysis.

Setting described. A course titled Women and Leadership served as the bounded context for the study. This elective course is one that I designed and taught in the Leadership Studies minor curriculum at a liberal arts institution. Two course sections offered in consecutive semesters were used for analysis. Each section enrolled 25 students; one section comprised 22 women and three men, whereas the other comprised 21 women and four men. The two sections were similar in structure and content. Both were offered in a traditional classroom setting.

I treated the course as one that addressed a sensitive subject and shaped the content and structure accordingly. Course topics included pros and cons of generalizing, stereotyping, and gendering leadership; why study women and leadership, and where do men fit into the conversation; brief history of women and leadership; gender roles, social roles, mental models, and implicit leadership theories; empirical findings and theories about gender and leadership styles, communication, and interaction styles, and their effectiveness; women, leadership, and the media; the pressure for women to have it all versus opt out, with emphasis on family-work balance; Millennial generation women and leadership; women and leadership in different cultures; women leaders and power; women leading in traditionally masculine fields; strategies for success, including authenticity; obstacles to women's leadership at the individual, organizational, and societal levels, and how to address them; and, strategies for change. I emphasized early and frequently my classroom philosophy of an open and respectful space among teacher and all students for exploration and learning, including a balance of speaking and listening, to the end that each student may feel comfortable engaging in what can be a messy learning process. Class sessions largely began with a short lecture and perhaps a video clip to introduce new concepts, followed by small or large group discussions and active learning activities. Guest speakers joined us a few times during the semester. Assignments included required readings, class participation and in-class reflective writings, public class blog contributions, interview papers, and a creative final project with presentation.

Participants described. Participants were 48 undergraduate students enrolled in the Women and Leadership course for either the Fall 2012 or Spring 2013 semester. Only two students chose not to participate. Of the participants, 39 (82\%) self-reported as women, five selfreported as men (11\%), and four (9\%) did not disclose their gender. The large majority of participants were of junior or senior standing; all were of traditional college age and pursuing a minor in Leadership Studies. These characteristics are particularly salient because participant demographics influence classroom dynamics, especially when the topics are sensitive (Gilbert \& Eby, 2001). Participants signed informed consent forms.

Data collection. I collected data using two sets of reflection questions distributed to participants during the first and final weeks of the semester. Participants completed their responses outside of class and anonymously submitted their written responses, to be shared only 
with me, using a code name of their choice. Questions included: (a) Why did you choose to enroll in a course about women and leadership?; (b) What are your expectations for how this course will go, given the topic?; (c) What are your concerns, if any, about digging into and discussing the topic of women and leadership?; (d) Now that you have almost completed this course, please describe your experience with discussing issues related to women and leadership in this course. Is your experience in this course what you had expected? Why or why not?; and (e) In what ways, if at all, has your thinking about women in general and women and leadership in specific changed over the semester?

Data analysis. Prior to data analysis, I re-coded participants' selected code names to retain participant confidentiality and maintain traceability to the original source for trustworthiness (Guba \& Lincoln, 1981; Merriam, 1998). The three major themes were assigned a priori based on the questions posed for this study. To determine the preliminary minor themes within each major theme, I first coded each data unit myself. I utilized the constant comparative method for data analysis because it is suitable for inductive, concept-building qualitative approaches (Glaser \& Strauss, 1967). First, I used open coding to identify concepts and group them into categories based on commonalities. Next, I used axial coding to confirm that the concepts and categories accurately represented the data, and to explore the analytic relationship between the concepts and categories (Strauss \& Corbin, 1990). I constructed and revised concepts and categories by continually comparing one unit of data to the next. Once I identified preliminary minor themes, two student assistants who were not participants in the study or courses at any time also independently coded each data unit to enhance trustworthiness (Guba \& Lincoln, 1981; Merriam, 1998). Student coders were provided with the major themes and the preliminary minor themes, and were instructed to use their judgment as to whether each data unit fit into a preliminary minor theme, fit into a new minor theme, or was an outlier. Minor themes and the data units they comprised were determined by strong agreement, with at least two of three coders in agreement. To be included as a minor theme, I applied the decision rule that 25 percent of responses had to exemplify the theme.

\section{Findings}

The findings are presented in two subsections: Students' Expectations of the Course and Students' Experiences with the Course. These two major themes were driven by the questions. The minor themes within each major theme emerged from students' responses.

Students' Expectations of the Course. At the second class session, students were asked about their expectations for how the course would go and their concerns about digging into and discussing the subject of women and leadership. The findings show that students anticipated both struggle and meaningful learning.

Struggle. Two main sources of anticipated struggle emerged: conflicting views and confrontation, including discussions being taken personally; and, possibility for narrow content and approach to the course. Students' expectations that the course would involve struggle was conveyed through their use of language such as: controversial, heated, rough spots, touchy or "hot button" topics, intense, difficult, challenging, and tough. Students recognized women and leadership as a sensitive subject that would pose challenges to teaching and learning. 
The concerns of 24 (57\%) of the 42 students who responded manifested in worry about how class members would deal with multiple, potentially conflicting views and opinions, and the likelihood of confrontation when discussing leadership from a gendered perspective. For instance, "some topics may upset some individuals because everyone has different opinions about the ability and quality of leadership coming from women." One student explicitly placed the subject of women and leadership in the larger societal context to note that a "BIG concern is religion and politics. That WILL get messy since both factors have their own view of women." As members of the Millennial generation, the students also struggled with conflicting views about the salience of gender in the discussion and practice of leadership. Some defend the notion that gender is no longer relevant in discussions of leadership, whereas others contend that gender can play a role. For Millennial generation students in particular, the value of openness to and tolerance of difference tends to transcend the salience of any particular personal or social identities (Martin \& Tulgan, 2001). Some even claim they “don't see" gender. On the contrary, gender is the first identity category that people notice (Stangor, Lynch, Duan, \& Glass, 1992). As much as Millennials may want to, or actually do, embrace impartiality when it comes to identities, the students in this study recognize that conflicting views about gender can make it a sensitive subject. One student was concerned about how conflict in the classroom would affect her experience, as she would "just choose to stay quiet even if I have a strong, valid point to make-because sometimes I'm really non-controversial."

Of the 24 students who noted concern about conflict and confrontation, seven of them anticipated further struggle through their expectation that discussions would be taken personally rather than viewed as a learning experience. They worried about strong opinions and classmates remaining respectful of others' views. This area of struggle itself was at times grounded in students" own gendered expectations: "Some classmates will be offended by intense discussion either by the males in our class or consequently each other. It's a very tough topic because most of us are women and we may get emotional in some discussions." Women and leadership may be a subject that is easily taken personally largely because most of the issues boil down to the concepts of power and privilege, and at times difference. Power, privilege, and difference themselves are sensitive topics, often fraught with confusion, blaming, denial, and resistance (Johnson, 2001). Although the underlying power and privilege, as well as the resultant gender and leadership issues, are largely socio-structural in nature, it is challenging for those engaging with the issues to maintain that broader perspective and resist personalizing the issues (Bohmer \& Briggs, 1991). Students in this study feared that taking the implications of socio-structural power and privilege to an individualized, personalized level would hinder the learning experience. The aforementioned fear of disagreement on gendered issues and the fear of discussions being taken personally may worry students that what happens inside the classroom will affect their relationships with their classmates outside of the classroom, and could influence them to resist active participation in discussion (Lusk \& Weinberg, 1994).

Students' second main area of anticipated struggle was about the possibility that the content and approach to class would be too narrow, as indicated by 11 of $42(26 \%)$ respondents. They were especially worried about class becoming a victimizing session focused on problems and not solutions. A female student proclaimed, "As there are an overwhelming majority of females in the class, I don't want to be stuck listening to a pity party. There's nothing more annoying than a group complaining about how unfair various aspects of life are without at least 
acknowledging that a solution exists." Another fretted that "instead of exploring solutions and newer perspectives, the class will be stuck on just learning the history and roots of prejudices behind women as powerful leaders." This concern reflects the typical Millennial generation quality of being solution- and action-oriented (Martin \& Tulgan, 2001). Concern about narrowness was also evident in responses of anticipation that the class would take on an excessively feminist slant - that the class would "always take the side of 'pro-woman,' 'woman power" and the feminists in the class would "harp on issues, but not steer towards solutions until prompted." Students worried that such a feminist bias would be frustrating or alienating for themselves or other students. This concern is likely grounded in younger generation members' reluctance to associate with feminism as a term and construct, and often to outright reject it, even though they are eager to explicitly support gender equality (Scharff, 2001).

Beyond the evident themes, three insightful outliers were also troubled about the potential for generalizations, stereotypes, and assumptions inevitably being brought into a gendered discussion of leadership. One student noted that she expected "a fair amount of struggle with generalizations, victimizing women, and polarizing the situation even though this topic cannot be understood in black and white thinking." Another claimed that "conversation might get heated at some points during the semester-stereotypes and assumptions about both genders are sure to get thrown around." Right or wrong, generalizations and stereotypes abound in the discussion of women and leadership (Rhode, 2003). One must be willing to think and talk in generalizations to even approach the subject. Although there is utility in lumping people together by a common identity for purposes of cognitive efficiency and understanding people of a shared identity "in general" (Brewer, 1996), doing so can be frustrating for those who realize that no one individual fully fits a stereotype. Labeling, making assumptions, and attributing qualities to people based on generalizations and stereotypes can particularly challenge people of a generation that touts the value of individual uniqueness (Martin \& Tulgan, 2001).

Meaningful learning. Despite their acknowledgements of potential struggle at the outset, 24 of $42(57 \%)$ students also expected meaningful learning to result from digging into and discussing the subject of women and leadership. They anticipated that discussions would expose them to different views, opinions, and interpretations that would contribute to their learning. Expectations of meaningful learning were conveyed through students' use of language such as: eye-opening, stretch mind, broader understanding, critical thinking, share ideas, gain knowledge, form own opinions, and thought-provoking discussions. Students expected "civilized but real controversy, which is always interesting and sheds light on different viewpoints-which will stretch my mind," and a "real learning experience with plenty of intense conversations."

\section{Students' Experiences with the Course}

At the course conclusion, students were asked to describe their experiences with discussing issues related to women and leadership, and how, if at all, their thinking about women and leadership in had changed over the semester. Their responses indicated that the approach to the course minimized their anticipated struggles and helped them to be able to engage in a meaningful learning experience, and that many experienced transformative learning.

Approach to course. Students appreciated the opportunity for exploration in the course provided by the approach to the course content, structure, and culture. Of 45 respondents, 20 
(44\%) explicitly noted ways in which the approach to the course minimized their anticipated struggles and facilitated their learning. Some noted that the content was not as narrowly focused as they had worried it would be. More topics, issues, and perspectives were integrated into classes and discussions than they had expected, and with depth beyond what they anticipated. One woman admitted, "I came into this class expecting to only hear a 'feminist' point of view but I was mistaken. After the first few weeks of class, I felt less like I had to defend my gender." She may have expected that the traditional gender role for women would be devalued in a course on women and leadership. Students also valued the structure that allowed them to learn from others and hear a variety of perspectives through different assignments, speakers, and an interactive, collaborative, discussion-based approach to sessions - an approach which helped them to "take a second to stop and think about the issue in a real way." This finding is not surprising, given that undergraduate Millennial generation students in leadership education believe that active participation, collaborative group work, and interactive discussions foster their learning (Wisniewski, 2010). Further, some students expressed the benefits of the course content and structure as an intellectually challenging experience. As one noted, "It's been really interesting to hear the perspectives of different students and I think this class has definitely been one of the most valuable ones I've taken... simply because the depth of which I've been sincerely challenged to think." Course content did have room for improvement, however, as three students revealed disappointment with not having more discussion focused on producing change and action, and "how to jump these hurdles and stop these issues from holding women leaders back."

Along with the course content and structure, students remarked that the course culture, and specifically the emphasis on a safe learning environment, positively influenced their experiences with the course. One student revealed that she pushed past her comfort zone to move from fear to engagement due to the culture of a safe environment: "When I first walked into the classroom and became more aware about the depth and heaviness of the content, I considered dropping the course altogether. I did not know if I would be able to participate...luckily, the class environment was supportive and open to different viewpoints." Another felt "better equipped to have difficult conversations or discussions as a result of this class...not only the materials but class discussions and environment aided in this realization." Based on her concerns about the subject, another student had needed the environment "to be a safe place... where I can express my opinion and feel comforted by the comments and remarks students make around me" in order to fully participate in discussions and learning.

Transformative learning. A transformative learning experience was evident when students were asked about the ways in which their thinking about women and leadership changed over the semester, and the ways in which they see or consider US culture/society or the world any differently regarding women and leadership. Almost all students indicated general learning, as their responses illustrated an increased complexity in their seeing and thinking, and a change in their behavior (Ambrose et al., 2010). They developed a heightened awareness of issues related to women and leadership (and gender in general), which would allow them to be more critical as leaders, followers, and citizens. One student wrote: "I realized I was blind to the stereotypes and issues facing women and leadership before experiencing this class. I feel comfortable discussing these issues because I feel like I have learned a lot. My eyes were opened to concrete material that I had never thought of before." However, for 18 of the 45 (40\%) respondents, learning went beyond general to be transformative, shown by an 
epistemological change in students' "ways of knowing" (Mezirow, 2000). In one case, a student "did not expect it [the class] to be to this influential on my view of the world, but it has impacted how I view the world around me and also the interactions I have with people on a daily basis." Another reflected on her shifting view of her own potential as a leader, "I used to view women in leadership in a negative light. I had the impression that women who were in leadership positions were extremely masculine, feminist in the negative connotation and that since I do not possess those qualities, that I would never even want to be a woman in a leadership position. This view has changed over the semester. I have realized that there are different types of leadership positions available to women, and while some do require masculine traits, I can still be a leader while maintaining my femininity within certain positions." For some, the transformative learning experience was surprising, such as for the student who revealed, "I really did not care about women and leadership and had quite a large bias against feminism or anything relating to it. But...I have gained exponential knowledge and really been challenged. There have been few other courses that have really made me question my assumptions and challenge my actions as this class." These responses, among others, show that students modified their taken-for-granted frames of reference to be more open, discriminating, and reflective (Mezirow, 2000).

\section{Discussion and Implications}

This study's findings indicate that students, in this case from the typically more openminded Millennial generation, perceive women and leadership as a sensitive subject fraught with potential struggles for learners, but are willing to engage in the subject in pursuit of meaningful learning. The findings also indicate that there is potential for transformative learning if the course content, structure, and learning environment are purposefully crafted to enable students to deal with anticipated or experienced struggles and engage in rather than resist the learning experience. The expectations and experiences of undergraduate students in this study have implications for leadership curriculum development, course design, and pedagogy.

Regarding leadership curriculum development, women and leadership should be considered a sensitive subject, but not one that should be avoided. The findings suggest that sensitive issues can be brought to the forefront and discussed in a way that is beneficial to students, and perhaps even to faculty. This conclusion should be reassuring for faculty who are wary of tackling sensitive issues among themselves and with students (Rusch, 2004). In support of Debebe's (2011) research on women's leadership transformation, it may be that leadership educators who address sensitive issues - in this case, gender - actually serve students not only by equipping them with another lens through which to analyze and practice leadership, but also by providing them with an opportunity for shifting paradigms regarding gender and leadership in society. Because students perceive women and leadership is perceived as a sensitive issue, leadership educators designing curricula may consider where to place such a course within the curriculum. It may be that students would be more open to engaging in this type of course if it came later in their curricular experience, after they have experienced other courses, formed faculty and peer relationships, know themselves better as learners, and had time to familiarize with the local learning culture. Research could investigate the relationship between curricular placement of sensitive issues courses and students' expectations and experiences. 
Students' expectations and experiences found in this study show the importance of designing courses on women and leadership to include a variety of content and diverse perspectives on issues, as well to provide a structure that offers students various ways to engage with the issues. Regarding content, when developing the Women and Leadership course I was mindful to choose a variety of relevant topics and include readings, assignments, and discussions that would allow for multiple perspectives to be explored. This variety of perspectives proved essential to students who were concerned about the content of a course on women and leadership being too narrow or biased toward a feminist, "man-hating" slant. However, a few students noted that their expectations were not met because we did not spend enough time addressing action- and change-oriented ideas. Indeed, leadership learners of the new millennium wish to apply their learning almost immediately (Huber, 2002). This finding may compel educators who teach sensitive issues to engage students in more reading and dialogue about what could be done to address those issues. A few other students' concerns also stress the importance of addressing the issue of generalizing and stereotyping at the beginning of and throughout the course. Regarding course structure, along with more communal learning endeavors, such as large group discussions and public blog contributions, I provided spaces for students to engage with course content in less vulnerable ways, such as small group discussions and private written reflections.

Beyond leadership curriculum development and course design, this study's findings have important implications for pedagogy. The finding that the approach to the course helped to quell students' anticipated struggles and fulfill their expectation of meaningful learning provides evidence that strategies for teaching sensitive issues that are advocated for in theory and practice can pay off in terms of enhancing students' willingness to engage and experience meaningful learning (e.g., Cherrin, 2004; Gilbert \& Eby, 2001; Lusk \& Weinberg, 1994). In particular, students' emphasis on a safe learning environment reflects the importance of practicing hospitality in the classroom, which provides a space of openness, respect, and care for what is typically a messy learning process (Palmer, 1993), and signifies students' need for intellectual safety. Providing an intellectually safe environment does not mean one in which students are protected from difficult conversations, provocative ideas, or disruptive perspectives. Based on research grounded in students' perceptions, Call defines intellectual safety as "an open and comfortable atmosphere in which students feel free to express their thoughts, feelings, or opinions without fear of retribution from instructors or peers" $(2007$, p. 28). The elements that help create intellectual safety include care, openness, motivation, and respect by the professor, as well as a classroom atmosphere of respect, openness, and engagement. Most of the students in this study were advanced enough in epistemological development to appreciate as intellectually safe an environment in which the teacher shares authority with students, allows room for uncertainty, engages students in collaborative knowledge construction and meaning making, and values diverse opinions and experiences (Schrader, 2004).

I utilized particular strategies to foster a safe learning environment, which for the sake of space cannot be elaborated upon here, but the strategies are not all new and are simply what have worked for me. Numerous teacher-scholars have published work that could be consulted as a resource for leadership educators interested in fostering intellectually safe learning environments (see, for example, Brookfield, 1995; Call, 2007; Cherrin, 2004; Cotton, 2006; Crosby, 2012; Debebe, 2011; Gilbert \& Eby, 2001; Lusk \& Weinberg, 1994; Jakubowski, 2001; Pace, 2003; Palmer, 1993; Schrader, 2004) and transformative learning (Mezirow, 2000; Taylor, 2000a). 
Each educator's approach must be tailored to their own strengths, limitations, personality, values, and teaching philosophy, among other factors. Further, creating such a space requires a collaborative effort with the students. Students are equally responsible, and deserve equal credit, for upholding such a space once they understand what it "looks like." Ultimately, creating an intellectually safe learning environment is an individualized, yet shared, context-specific endeavor between teacher and students, and is more a work of art than a collection of strategies.

While other factors can be considered, the safe learning environment that students referred to likely played a role in their experience of transformative learning (Mezirow, 1991). I crafted the environment to encourage trustful relationships and constructive discourse, and included many of the other conditions that Taylor (2000a) noted as key for transformative learning (see Relevant Literature section). I also utilized gender-sensitive teaching and learning practices, which are useful for transformative learning when the subject is women and leadership (Debebe, 2011). Leadership educators may consider utilizing some of these approaches when teaching about women and leadership in order to foster transformative learning.

Although this study focused on a Women and Leadership course taught within a larger curriculum and in a traditional classroom at a liberal arts college, the implications may be relevant for leadership educators teaching about women and leadership outside of academe, such as in business, community, or non-profit leadership development. They may also be relevant for those teaching the subject in non-traditional academic settings, such as online courses or academic institutions offering leadership development opportunities for businesses or community members. However, the results of this study could be biased by context and may not be highly generalizable. This study took place at a particular public, liberal arts institution; a course on women and leadership taught at other types of institutions may draw students or faculty with different motives, expectations, and approaches to such a course. Further, teaching about women and leadership outside of a traditional higher education classroom will likely make contextual differences salient. Future research that investigates the questions posed in this study at different types of institutions and organizations would be useful. One line of research may also consider the effects of a gender-homogenous environment on students' expectations and experiences, as well as the benefits and limitations of such an environment on transformative learning (for all genders), in order to build on Debebe's (2011) research that shows that women felt it was easier to broach gender-related issues when learning strictly with other women.

Some limitations of this study provide direction for additional research. Because the data were drawn from sets of pre-established reflective questions, I could not probe the respondents for details beyond what they submitted. Thus, the initial questions drove the narrative and likely limited the narrative focus. There are far more nuances to these questions that could be investigated in future research. Future research could also focus on transgender and transsexual students, because their expectations and experiences with a course on women and leadership may be different than those of the students in this study. Finally, additional research could investigate the expectations and experiences of students taking a course on women in leadership in other cultures that have different gender norms and representation of women in leadership positions. 


\section{Conclusion}

This study examined students' expectations of and experiences with studying women and leadership. The study is significant because it not only adds to the scarce existing literature on teaching the subject of women and leadership, it extends the existing literature on teaching sensitive issues by affirming its applicability to the subject of women and leadership - a subject often not acknowledged as sensitive. Additional research on this topic in various contexts, with different types of students, and utilizing different methods is called for to build upon this study's findings and to help inform the theory and practice of teaching women and leadership specifically, and teaching sensitive issues in general.

\section{References}

Ambrose, S. A., Bridges, M. W., DiPietro, M., Lovett, M. C., \& Norman, M. R. (2010). How learning works: Seven research-based principles for smart teaching. San Francisco: Jossey-Bass.

Bohmer, S., \& Briggs, J. L. (1991). Teaching privileged students about gender, race, and class oppression. Teaching Sociology, 19(2), 154-163.

Bomia, L., Beluzo, L., Demeester, D., Elander, K., Johnson, M., \& Sheldon, B. (1997). The impact of teaching strategies on intrinsic motivation. Champaign, IL: ERIC Clearinghouse on Elementary and Early Childhood Education.

Brewer, M. B. (1996). When stereotypes lead to stereotyping: The use of stereotypes in person perception. In C. N. Macrae, C. Stangor, \& M. Hewstone (Eds.), Stereotypes and stereotyping (pp. 254-275). New York: The Guilford Press.

Brookfield, S. (1995). Becoming a critically reflective teacher. San Francisco: Jossey-Bass.

Brown, G., Irby, B. J., Fisher, A., \& Yang, L. (2006). Using the andragogical model for a graduate course in educational leadership. The Delta Kappa Gamma Bulletin, Winter, $32-62$.

Call, C. M. (2007). Defining intellectual safety in the college classroom. Journal on Excellence in College Teaching, 18(3), 19-37.

Canagarajah, S. (2004). Subversive identities, pedagogical safe houses, and critical learning. In B. Norton \& K. Toohey (Eds.), Critical Pedagogies and Language Learning (pp. 116137). New York: Cambridge University Press.

Carini, R. M., Kuh, G. D., \& Klein, S. P. (2006). Student engagement and student learning: Testing the linkages. Research in Higher Education, 47(1), 1-32.

Cherrin, S. (2004). Teaching controversial issues. The Professional and Organizational Development Network in Higher Education. 
Cotton, D. R. E. (2006). Teaching controversial environmental issues: Neutrality and balance in the reality of the classroom. Educational Research, 48(2), 223-241.

Crosby, D. B. (2012). Meeting the challenge: Teaching sensitive subject matter. The Journal of Effective Teaching, 12(2), 91-104.

Debebe, G. (2011). Creating a safe environment for women's leadership transformation. Journal of Management Education, 35(5), 679-712.

Eagly, A. H., \& Carli, L. L. (2007). Through the labyrinth: The truth about how women become leaders. Boston: Harvard Business Review Press.

Eagly, A. H., \& Johnson, B. T. (1990). Gender and leadership style: A meta-analysis. Psychological Bulletin, 108(2), 233-256.

Eagly, A. H., Johannesen-Schmidt, M. C., \& van Engen, M. L. (2003). Transformational, transactional, and laissez-faire leadership styles: A meta-analysis comparing women and men. Psychological Bulletin, 129(4), 569-591.

Ely, R. J., Ibarra, H., \& Kolb, D. M. (2011). Taking gender into account: Theory and design for women's leadership development programs. Academy of Management Learning \& Education, 10(3), 474-493.

Gilbert, P. R., \& Eby, K. K. (2001). Blowing the teachers away: Teaching controversial and sensitive issues to undergraduates. Journal on Excellence in College Teaching, 12(2), 37-54.

Glaser, B. G., \& Strauss, A. L. (1967). The discovery of grounded theory. Chicago: Aldine.

Guba, E. G., \& Lincoln, Y. S. (1981). Effective evaluation. San Francisco: Jossey-Bass.

Gutman, A. (1988). Democratic theory and the role of teachers in democratic education. In J. Hannaway \& R. Crowson (Eds.), The politics of reforming school administration: The 1988 yearbook of the Politics of Education Association (pp. 183-199). New York: Falmer Press.

Helgesen, S. (1990). The female advantage: Women's ways of leadership. New York: Doubleday.

Hewlett, S. A. (2007). Off-ramps and on-ramps: Women's nonlinear career paths. In B. Kellerman \& D. L. Rhode (Eds.), Women and leadership: The state of play and strategies for change (pp. 407-430). San Francisco: Jossey-Bass.

Huber, N. S. (2002). Approaching leadership education in the new millennium. Journal of Leadership Education, 1(1), 25-34. 
Jakubowski, L. M. (2001). Teaching uncomfortable topics: An action-oriented strategy for addressing racism and related forms of difference. Teaching Sociology, 29(1), 62-79.

Johnson, A. G. (2001). Privilege, power, and difference. ( $1^{\text {st }}$ ed.). New York: McGraw-Hill.

Kellerman, B. (2012). The end of leadership. New York: HarperCollins.

Kuh, G. D. (1993). Ethos: Its influence on student learning. Liberal Education, 79(4), 22-31.

Kuh, G. D., Kinzie, J., Schuh, J. H., \& Whitt, E. J. (2010). Student success in college: Creating conditions that matter. San Francisco: Jossey-Bass.

Lee, C. D. (2009). Cultural influences on learning. In J. A. Banks (Ed.), The Routledge international companion to multicultural education. New York: Routledge.

Leithwood, K., Louis, K. S., Anderson, S., \& Wahlstrom, K. (2009). How leadership influences student learning: A review of research from the Learning from Leadership Project. New York: The Wallace Foundation.

Lusk, A. B., \& Weinberg, A. S. (1994). Discussing controversial topics in the classroom: Creating a context for learning. Teaching Sociology, 22(4), 301-308.

Marshall, C., \& Rossman, G. B. (2011). Designing qualitative research $\left(5^{\text {th }}\right.$ ed.). Thousand Oaks CA: Sage.

Martin, C. A., \& Tulgan, B. (2001). Managing Generation Y: Global citizens born in the late seventies and early eighties. Amherst, MA: HRD Press.

Merriam, S. B. (1998). Qualitative research and case study applications in education. San Francisco: Jossey-Bass.

Mezirow, J. (1991). Transformative dimensions of adult learning. San Francisco: Jossey-Bass.

Mezirow, J. (1997). Transformative learning: Theory to practice. In P. Cranton (Ed.), Transformative learning in action: Insights from practice. New directions for adult and continuing education, No. 74. San Francisco: Jossey-Bass.

Mezirow, J. (2000). Learning to think like an adult: Core conceptions of transformation theory. In J. Mezirow (Ed.), Learning as transformation: Critical perspectives on a theory in progress (pp. 3-33). San Francisco: Jossey-Bass.

Miles, M. B., \& Huberman, A. M. (1994). Qualitative data analysis ( $2^{\text {nd }}$ ed.). Thousand Oaks CA: Sage. 
Pace, D. (2003). Controlled fission: Teaching supercharged subjects. College Teaching, 51(2), 42-45.

Palmer, P. (1993). To know as we are known. San Francisco: HarperOne.

Pittinsky, T. L., Bacon, L. M., \& Welle, B. (2007). The great women theory of leadership? Perils of positive stereotypes and precarious pedestals. In B. Kellerman \& D. L. Rhode (Eds.), Women and leadership: The state of play and strategies for change (pp. 93-125). San Francisco: Jossey-Bass.

Rhode, D. L. (2003). The difference "difference" makes: Women and leadership. Redwood City, CA: Stanford University Press.

Riggio, R. E., Ciulla, J. B., \& Sorenson, G. J. (2003). Leadership education at the undergraduate level: A liberal arts approach to leadership development. In S. E. Murphy \& R. E. Riggio (Eds.), The future of leadership development (pp. 223-236). Mahwah, NJ: Lawrence Erlbaum Associates.

Rusch, E. A. (2004). Gender and race in leadership preparation: A constrained discourse. Educational Administration Quarterly, 40(1), 14-46.

Sandberg, S. (2013). Lean in: Women, work and the will to lead. New York: Knopf.

Scharff, C. (2012). Repudiating feminism: Young women in a neoliberal world. Farnham, England: Ashgate.

Schrader, D. E. (2004). Intellectual safety, moral atmosphere, and epistemology in college classrooms. Journal of Adult Development, 11(2), 87-101.

Schwartz, M. K., Axtman, K. M., \& Freeman, F. H. (Eds.). Leadership education: A sourcebook of courses and programs $\left(7^{\text {th }}\right.$ ed.). Greensboro, NC: Center for Creative Leadership.

Sharpe, R. (2000, Nov. 20). As leaders, women rule. Bloomberg Business Week. Retrieved from: http://www.businessweek.com/2000/00_47/b3708145.htm

Slaughter, A. (2012, June 13). Why women still can't have it all. The Atlantic. Retrieved from: http://www.theatlantic.com/magazine/archive/2012/07/why-women-still-cant-have-it all/309020/

Spar, D. (2013). Wonder women: Sex, power, and the quest for perfection. New York: Sarah Crichton Books.

Stangor, C., Lynch, L., Duan, C., \& Glass, B. (1992). Categorization of individuals on the basis of multiple social features. Journal of Personality and Social Psychology, 62(2), 207218. 
Strauss, A., \& Corbin, J. (1990). Basics of qualitative research: Grounded theory procedures and techniques. Thousand Oaks CA: Sage.

Taylor, E. W. (2000a). Analyzing research on transformative learning theory. In J. Mezirow (Ed.), Learning as transformation: Critical perspectives on a theory in progress (pp. 285-328). San Francisco: Jossey-Bass.

Taylor, K. (2000b). Teaching with developmental intention. In J. Mezirow (Ed.), Learning as transformation: Critical perspectives on a theory in progress (pp. 151-180). San Francisco: Jossey-Bass.

Tuhus-Dubrow, R. (2009, May 3). The female advantage. The Boston Globe. Retrieved from: http://www.boston.com/bostonglobe/ideas/articles/2009/05/03/the_female_advantage/?pa ge $=1$

Umbach, P. G., \& Wawrzynski, M. R. (2005). Faculty do matter: The role of college faculty in student learning and engagement. Research in Higher Education, 46(2), 153-184.

Vinnicombe, S., \& Singh, V. (2002). Women-only management programs: An essential part of women's leadership development. Journal of Change Management, 3(4), 294-306.

Wang, M. C., Haertel, G. D., \& Walberg, H. J. (1990). What influences learning? A content analysis of review literature. The Journal of Educational Research, 84(1), 30-43.

Wisniewski, M. A. (2010). Leadership and the Millennials: Transforming today's technological teens into tomorrow's leaders. Journal of Leadership Education, 9(1), 53-67.

Yin, R. K. (2009). Case study research: Design and methods. Thousand Oaks, CA: Sage.

\section{Author Biography}

Dr. S. Lynn Shollen is Assistant Professor of Leadership Studies in the Department of Leadership and American Studies at Christopher Newport University, Newport News, Virginia. Her research interests include identity and perceptions of leadership, the effects on identity of the transition from faculty to academic administrator, teaching about women and leadership, and leadership identity construction. Her early research focused on faculty mentoring, particularly for women and racial minority faculty, including those interested in pursuing administrative leadership roles. Dr. Shollen co-authored the book Faculty Success Through Mentoring: A Guide for Mentors, Mentees, and Leaders (2009). She serves on the Executive Leadership Team of the International Leadership Association's Women and Leadership Affinity Group, as a reviewer for Journal of Leadership Education and Leadership, and on the advisory board for Christopher Newport University's Center for Effective Teaching. 